\title{
FLASH VACUUM PYROLYSIS OF LIGNIN MODEL COMPOUNDS: REACTION PATHWAYS OF AROMATIC METHOXY GROUPS
}

\author{
Phillip F. Britt, A. C. Buchanan, III, and Dan R. Martineau \\ Chemical and Analytical Sciences Division, Oak Ridge National Laboratory \\ P. O. Box 2008, MS-6197, Oak Ridge, TN 37831-6197 \\ Keywords: Pyrolysis mechanisms, lignin, model compounds

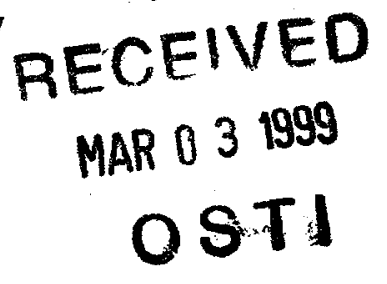

\section{ABSTRACT}

Currently, there is interest in utilizing lignin, a major constituent of biomass, as a renewable source of chemicals and fuels. High yields of liquid products can be obtained from the flash or fast pyrolysis of biomass, but the reaction pathways that lead to product formation are not understood. To provide insight into the primary reaction pathways under process relevant conditions, we are investigating the flash vacuum pyrolysis (FVP) of lignin model compounds at $500^{\circ} \mathrm{C}$. This presentation will focus on the FVP of $\beta$-ether linkages containing aromatic methoxy groups and the reaction pathways of methoxy-substituted phenoxy radicals.

\section{INTRODUCTION}

The thermochemical conversion of lignin, the second-most abundant naturally occurring biopolymer and a by-product of the pulping process, into higher value products is of interest as a consequence of its availability and its potential to produce higher value products [1]. However, in spite of the extensive research to expand the use of lignin, the efforts have been only moderately successful [2]. To enhance the economic production of liquid products from lignin, it is necessary to understand those factors that maximize product yields and promote product selectivity. Currently, the most promising process to maximize the yields of liquid products from biomass and lignin is flash or fast pyrolysis in which the substrate is heated to moderate temperatures, typically $500^{\circ} \mathrm{C}$, for contact times typically less than two seconds [3]. However, the fundamental chemical reactions that lead to the complex array of products remain poorly understood, and there is little insight into how to control product selectivity [4]. This is a consequence of the chemical and structural diversity of the lignin, the complexity of the product mixture, and the thermal instability of the primary products [1-4]. To overcome some of these complexities, we are investigating pyrolysis of compounds which model key structural features found in lignin to gain mechanistic insight into the reaction pathways and products [5].

To investigate the pyrolysis reactions at short contact times, lignin model compounds will be investigated by flash vacuum pyrolysis (FVP). In FVP experiments, the substrate is sublimed through a pyrolysis tube (at $500{ }^{\circ} \mathrm{C}$ for this study) under vacuum $\left(<10^{-3} \mathrm{~mm} \mathrm{Hg}\right.$ ) and the products are quenched at low temperatures, typically $77 \mathrm{~K}$. The contact time is typically $<0.1 \mathrm{~s}$ and there are low steady-state concentrations of the reactants and products in the hot zone so that only very fast bimolecular reactions (such as radical-radical coupling reactions) can occur. Thus, the primary reaction pathways and reactive intermediates can be identified with a minimum of interference from bimolecular reactions. In future studies, the pyrolysis will be investigated at higher pressures $(0.1 \mathrm{~mm} \mathrm{Hg}$ to 1 atmosphere) under a flow of inert gas to determine the more complex secondary reaction pathways. 


\section{DISCLAIMER}

This report was prepared as an account of work sponsored by an agency of the United States Government. Neither the United States Government nor any agency thereof, nor any of their employees, make any warranty, express or implied, or assumes any legal liability or responsibility for the accuracy, completeness, or usefulness of any information, apparatus, product, or process disclosed, or represents that its use would not infringe privately owned rights. Reference herein to any specific commercial product, process, or service by trade name, trademark, manufacturer, or otherwise does not necessarily constitute or imply its endorsement, recommendation, or favoring by the United States Government or any agency thereof. The views and opinions of authors expressed herein do not necessarily state or reflect those of the United States Government or any agency thereof. 


\section{DISCLAIMER}

Portions of this document may be illegible in electronic image products. Images are produced from the best available original document. 
Lignin is a complex, heterogeneous, three-dimensional polymer formed from the enzymeinitiated, dehydrogenative, free-radical polymerization of three $p$-hydroxycinnamyl alcohol precursors that differ by the number of methoxy groups on the aromatic ring [1a, 6]. As opposed to other biopolymers such as cellulose, lignin has many different types of linkages between monomer units. The dominant interunit linkage in lignin is the arylglycerol- $\beta$-aryl ether linkage, commonly referred to as the $\beta-O-4$ linkage which accounts for approximately $48-60 \%$ of the total interunit linkages $[1 \mathrm{a}, 6]$, exemplified by the structure below. If this structure is<smiles>[R]c1cc(C([X])C([Y])Oc2c([R])cc(C)cc2[R])cc([R])c1O[Na]</smiles>

$$
\begin{aligned}
& \mathrm{R}=\mathrm{H} \text { or } \mathrm{OCH}_{3} \\
& \mathrm{X}=\mathrm{OH}, \mathrm{OAr} \text { or }=\mathrm{O} \\
& \mathrm{Y}=\mathrm{CH}_{2} \mathrm{OH} \text { or } \mathrm{CH}_{2} \mathrm{OR}
\end{aligned}
$$

stripped for all its substituents, the skeletal remnant would be phenethyl phenyl ether $\left(\mathrm{PhCH}_{2} \mathrm{CH}_{2} \mathrm{OPh}\right)$, the simplest model of the $\beta-\mathrm{O}-4$ linkage, and the starting point for this mechanistic investigation.

In this investigation, the FVP of phenethyl phenyl ether (1), phenethyl $o$-methoxyphenyl ether (2), and phenethyl 2,6-dimethoxyphenyl ether (3) was studied at $500{ }^{\circ} \mathrm{C}$ under low pressures $\left(<10^{-3} \mathrm{mmHg}\right)$ to determine the impact of methoxy substituents on the reaction pathways of the $\beta-O-4$ linkage of lignin. The methoxy-substitutents accelerate the decomposition of the $\beta-O-4$ linkage and produce a complex array of products by a variety of reaction channels. Surprisingly, $\boldsymbol{o}$-cresol was the major product in the FVP of 3 . The reaction pathways for the decomposition of 1-3 and the formation of products are discussed below.

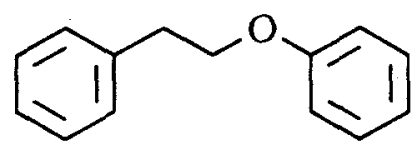

1<smiles>COc1ccccc1OCCc1ccccc1</smiles>

2<smiles>COc1cccc(OC)c1OCCc1ccccc1</smiles>

3

\section{EXPERIMENTAL}

Analyses were performed on a Hewlett-Packard 5890 Series II gas chromatograph equipped with a J\&W $30 \mathrm{~m} \times 0.25 \mathrm{~mm}$ i.d. (0.25 $\mu \mathrm{m}$ film thickness) DB-1 methylsilicone capillary column, a flame ionization detector, and a Hewlett-Packard 7673 autosampler. Detector response factors were determined for authentic samples relative to cumene, diphenyl ether, and 3,5dimethylphenol or 3,4-dimethylphenol as internal standards or were based on carbon number. Mass spectra were obtained at $70 \mathrm{eV}$ on a Hewlett-Packard $5972 \mathrm{GC} / \mathrm{MS}$ equipped with a capillary column identical to that used for $\mathrm{GC}$ analysis.

The syntheses of phenethyl phenyl ether (1) and $\mathrm{PhCD}_{2} \mathrm{CH}_{2} \mathrm{OPh}\left(1-d_{2}\right)$ have been previously described [5b]. Phenethyl o-methoxyphenyl ether (2) and phenethyl 2,6dimethoxyphenyl ether (3) were prepared by coupling 2-phenylethyl tosylate with guaiacol or 2.6-dimethoxyphenol in DMF with $\mathrm{K}_{2} \mathrm{CO}_{3}$ [5]. All compounds were purified by vacuum fractional distillation: $2,99.8 \%$ purity by GC: bp $109-110^{\circ} \mathrm{C}(0.05 \mathrm{mmHg}) ; \mathrm{MS} m / z$ (relative intensity) 228 (32), 124 (16), 109 (11), 105 (100), 103 (12), 91 (9), 79 (18), 77 (32); 3, 99.5\% 
purity by GC: bp $138-139{ }^{\circ} \mathrm{C}(0.025 \mathrm{mmHg})$; $\mathrm{MS} \mathrm{m} / \mathrm{z}$ (relative intensity) 258 (36), 154 (43), 139 (10), 105 (100), 103 (10), 95 (11), 91 (5), 79 (15), 77 (18).

The FVP apparatus was based on the design reported by Trahanovsky and has been previously described [5a, 7]. All pyrolyses were run at $<10^{-3} \mathrm{mmHg}$ and at $500 \pm 1{ }^{\circ} \mathrm{C}$. Sample throughput was typically $50-100 \mathrm{mg} \mathrm{h}^{-1}$. Under these conditions, contact time is estimated at 2 $\mathrm{ms}$ and the steady state concentration of materials in the hot zone is $10^{-9}-10^{-10} \mathrm{~mol} \mathrm{~L}^{-1}[8]$. To check the long term reproducibility of the pyrolysis reactor to ensure that the relative reactivity of the substituted phenethyl phenyl ethers could be compared over time, the FVP of $\mathbf{2}$ was run after every $4-5$ pyrolyses as a control sample. Similar pyrolysis results $( \pm 10 \%)$ have been obtained for 2 over a six-month period.

\section{RESULTS AND DISCUSSION}

FVP of 1. The major products from the FVP of 1 at $500{ }^{\circ} \mathrm{C}$ are shown below (average mol $\%$ from three runs). As a consequence of the low \% conversions $(0.94 \pm 0.16 \%)$, the reproducibility and the mass balances $(95 \pm 3 \%$ ) were not as good as that found at higher conversions. In addition to the products shown below, a small amount (typically, $\leq 1 \%$ of the starting material) of rearranged 1,o-(2-phenylethyl)phenol and $p$-(2-phenylethyl)phenol, was also found. At higher temperatures $\left(550\right.$ and $\left.600{ }^{\circ} \mathrm{C}\right)$, the conversion of 1 increased to form the products shown above, but the yield of the rearranged products did not increase. It seems unlikely that the phenoxy and phenethyl radicals underwent recombination since no crosscoupling products, phenoxyphenol or 1,4-diphenylbutane, were observed [7b]. Therefore, the rearranged products were attributed to a small amount of acid catalysis from the quartz chips.

The major products from the FVP of 1 can be formed by cleavage of the $\mathrm{C}-\mathrm{O}$ bond, i.e. the weakest bond in the molecule $\left(D^{\circ}{ }_{\mathrm{C}-\mathrm{O}}\right.$ and $D^{\circ}{ }_{\mathrm{C}-\mathrm{C}}$ estimated as 63 and $72 \mathrm{kcal} \mathrm{mol}^{-1}$, respectively) [5a]. Homolytic cleavage of the $\mathrm{C}-\mathrm{O}$ bond forms $\mathrm{PhO} \cdot$ which can pick up a hydrogen atom from the walls of the reactor to form $\mathrm{PhOH}$ [9] and $\mathrm{PhCH}_{2} \mathrm{CH}_{2} \bullet$ which can lose a hydrogen atom by $\beta$ scission to form $\mathrm{PhCH}=\mathrm{CH}_{2}$. In the decomposition of an analogous alkyl phenyl ether, $n$-butyl phenyl ether, it was proposed that products were formed by $\mathrm{C}-\mathrm{O}$ homolysis $\left(\log \mathrm{k}\left(\mathrm{s}^{-1}\right)=16.0\right.$ $65.5 \mathrm{kcal} \mathrm{mol}^{-1} / 2.303 \mathrm{RT}$ ) and by 1,2-elimination through a four centered transition state (log k $\left.\left(\mathrm{s}^{-1}\right)=13.6-57.4 \mathrm{kcal} \mathrm{mol}^{-1} / 2.303 \mathrm{RT}\right)[10]$. At $500{ }^{\circ} \mathrm{C}$. the ratio of homolysis to $1,2-$
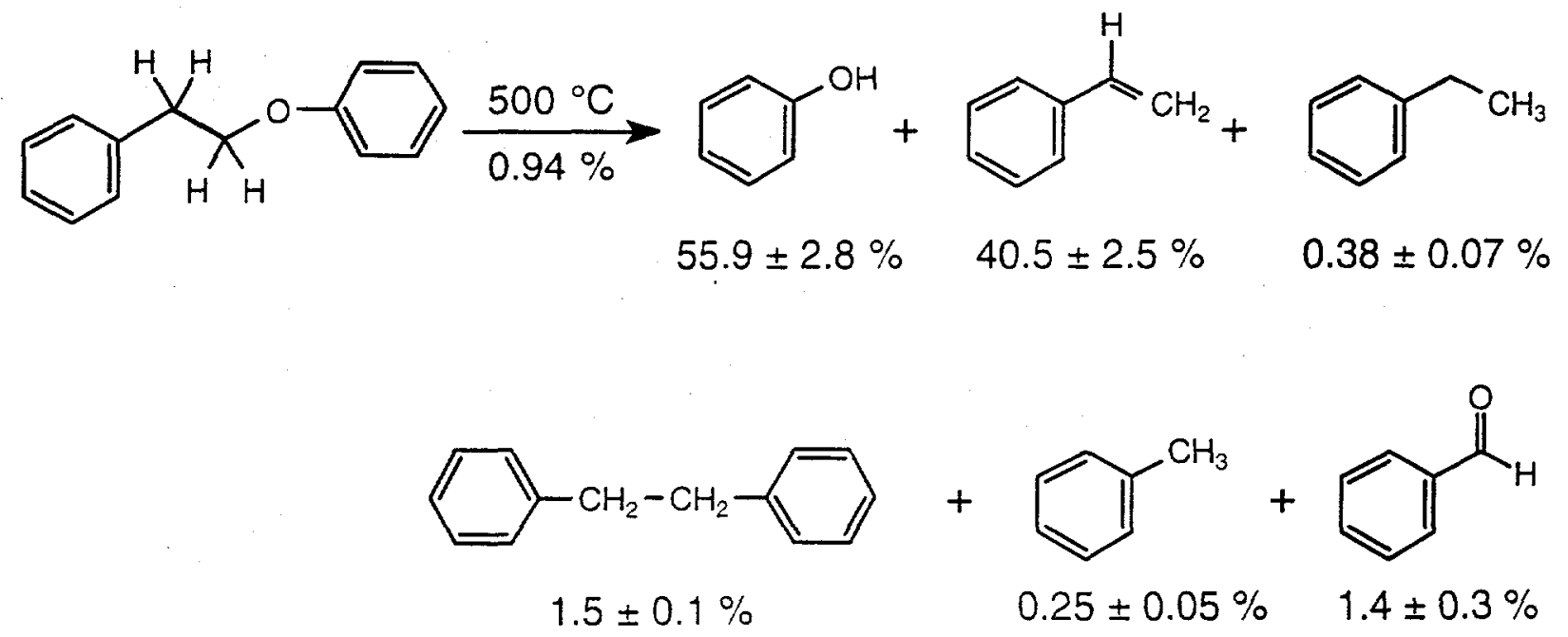
elimination is calculated to be 1.3:1. In the pyrolysis of 1,1,2-elimination would also produce styrene and phenol so that it is very difficult to deconvolute the homolysis and 1,2-elimination pathways in the decomposition of 1 since both routes lead to the same products. However, if 1 is substituted with deuterium in the benzylic position $\left(\mathrm{PhCD}_{2} \mathrm{CH}_{2} \mathrm{OPh}, 1-d_{2}\right)$, the rate of 1,2elimination would be slower, as a consequence of the deuterium isotope effect in breaking the $\mathrm{C}$ $\mathrm{D}$ bond in the transition state, while the homolytic cleavage should not be influenced by the substitution. At $500{ }^{\circ} \mathrm{C}$, a maximum rate difference $\left(\mathrm{k}_{\mathrm{H}} / \mathrm{k}_{\mathrm{D}}\right.$ in the absence of tunneling) of 2.1 is predicted for the 1,2-eliminination of 1 . In the pyrolytic 1,2-elimination of hydrogen halide from ethyl chloride, ethyl bromide, and their deuterated analogues, the measured isotope effect was $\left(\mathrm{k}_{\mathrm{H}} / \mathrm{k}_{\mathrm{D}}\right) 2.0-2.2$ at $500{ }^{\circ} \mathrm{C}[11]$. Comparison of the \% conversion from three FVP runs of $1-d_{2}$ and 1 under similar conditions found that $1-d_{2}$ reacted approximately $20 \%$ slower than 1 indicating that the 1,2-elimination contributes to the decomposition of 1 at low pressures [12]. At higher pressures, radicals produced from $\mathrm{C}-\mathrm{O}$ homolysis can start chain reactions and the contribution of 1,2-elimination will be small.

A small amount of toluene, bibenzyl, and benzaldehyde are formed from $\mathrm{C}-\mathrm{C}$ homolysis. Under the low-pressure reaction conditions, a majority of the benzyl radicals couple to form bibenzyl. The phenoxymethyl radical $\left(\mathrm{PhOCH}_{2}{ }^{\circ}\right)$ produces benzaldehyde by a 1,2-phenyl shift, to form the benzyloxy radical $\left(\mathrm{PhCH}_{2} \mathrm{O} \bullet\right)$, followed by loss of a hydrogen atom. The Arrhenius parameters for the formation of benzaldehyde from the phenoxymethyl radical ( $\mathrm{PhOCH} 2 \cdot$ ) have been reported as $\log \mathrm{k}\left(\mathrm{s}^{-1}\right)=12.5-21 \mathrm{kcal} \mathrm{mol}^{-1} / 2.303 \mathrm{RT}$ [13]. $\beta$-Scission of the benzyloxy radical to form the phenyl radical and formaldehyde $\left(\log \mathrm{k}^{-1}\left(\mathrm{~s}^{-1}\right)=14.0-24.5 \mathrm{kcal} \mathrm{mol}^{-1} /\right.$ $2.303 \mathrm{RT})$ is approximately 100 -times slower than loss of a hydrogen atom $\left(\log \mathrm{k}^{-1} \mathrm{~s}^{-1}\right)=13.9$ $17.2 \mathrm{kcal} \mathrm{mol}^{-1} / 2.303 \mathrm{RT}$ ) [14]. Thus, benzene is not predicted to be a primary pyrolysis product.

FVP of 2. The major products from FVP of 2 are shown below (average mol $\%$ from six runs). The conversion and mass balance for the FVP of 2 was $3.8 \pm 0.2 \%$ and $98.2 \pm 4.6 \%$, respectively. Only a small amount $(5.0 \pm 2.2 \mathrm{~mol} \%)$ of rearranged starting material (2-(2phenylethyl)-6-methoxyphenol) was observed indicating that the surface mediated, acidcatalyzed reactions are of minor importance.

The decomposition of $\mathbf{2}$ is ca. four times faster than that for $\mathbf{1}$. On the basis of the FVP results of 1 , the major products should arise from $\mathrm{C}-\mathrm{O}$ homolysis and 1,2-elimination. The $o$ methoxy group is expected to accelerate the homolysis of the $\beta$-ether linkage since $o$-and $p$ methoxy groups have been shown to lower the bond dissociation energy of anisole by $4 \mathrm{kcal} \mathrm{mol}^{-}$ ${ }^{1}[15]$. This would correspond to a rate enhancement of 13.5 at $500{ }^{\circ} \mathrm{C}$. Homolysis of the $\mathrm{O}-\mathrm{CH}_{3}$ bond of the methoxy group is expected to be approximately four times slower than that for $\mathrm{O}-\mathrm{CH}_{2} \mathrm{CH}_{2} \mathrm{Ph}$ basis on the average Arrhenius parameters for the homolysis of anisole $\left(\mathrm{PhOCH}_{3}\right)$ and phenetole $\left(\mathrm{PhOCH}_{2} \mathrm{CH}_{3}\right)$ [16]. The rate of 1,2-elimination is predicted to be less sensitive to the methoxy substituent on the basis of the similar Arrhenius parameters obtained in the 1,2-elimination of iso-butylene from phenyl tert-butyl ether $\left(\log \mathrm{k}\left(\mathrm{s}^{-1}\right)=14.3 \pm 0.2-50.4 \pm\right.$ $\left.0.7 \mathrm{kcal} \mathrm{mol}^{-1} / 2.303 \mathrm{RT}\right)$ and $p$-methoxyphenyl tert-butyl ether $\left(\log \mathrm{k}\left(\mathrm{s}^{-1}\right)=14.5 \pm 0.3-50.2 \pm\right.$ $0.9 \mathrm{kcal} \mathrm{mol}^{-1} / 2.303 \mathrm{RT}$ ) [17]. Therefore, in addition to $\mathrm{C}-\mathrm{O}$ homolysis, 1,2-elimination must have a significant contribution to the overall rate of decomposition of $\mathbf{2}$, since the full rate enhancement predicted for the methoxy substitutent was not realized. 


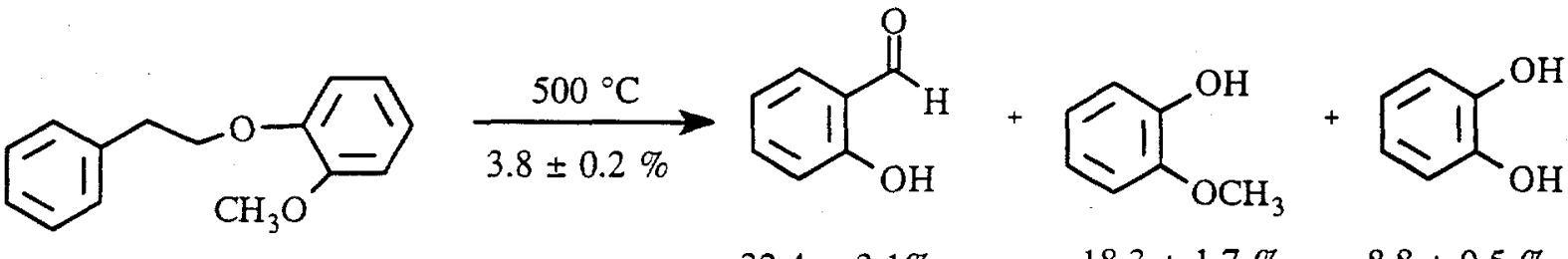

$32.4 \pm 3.1 \%$

$18.3 \pm 1.7 \%$

$8.8 \pm 0.5 \%$<smiles>Oc1ccccc1</smiles><smiles>C=Cc1ccccc1</smiles><smiles>[CH2+]Cc1ccccc1</smiles><smiles>Cc1ccccc1</smiles>

$7.5 \pm 1.0 \%$

$19.7 \pm 0.7 \%$

$2.9 \pm 0.2 \%$

$0.56 \pm .15 \%$

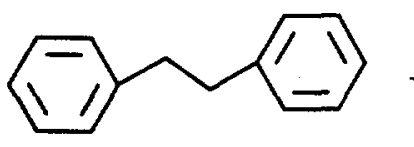

$0.77 \pm 0.04 \%$

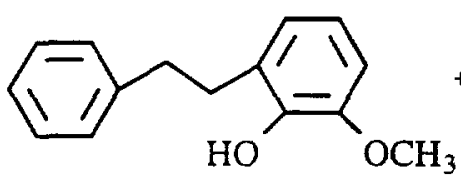

$5.0 \pm 2.2 \%$<smiles>COc1ccccc1C=O</smiles>

$1.6 \pm 0.3 \%$

The reaction pathways for the formation of the major products from the FVP of 2 are shown below. 1,2-Elimination from 2 produces styrene and guaiacol (not shown). Homolysis of $\mathrm{C}-\mathrm{O}$ bond in 2 produces the $o$-methoxyphenoxy radical and the phenethyl radical, which will form styrene by $\beta$-scission of a hydrogen atom. The $o$-methoxyphenoxy radical can abstract hydrogen internally through a six-centered transition state to form the $o$-hydroxyphenoxymethyl radical. No guaiacol should be formed since internal hydrogen abstraction is fast compared to bimolecular wall associated hydrogen abstraction reactions [9]. Mulder has also shown that in the atmospheric pressure pyrolysis of dimethoxybenzene, hydrogen abstraction by $o$ methoxyphenoxy radical from a ten-fold excess of $p$-fluorotoluene is slower than internal hydrogen abstraction [18]. The $o$-hydroxyphenoxymethyl radical can undergo a 1,2-phenyl shift, similar to that discussed above for the phenoxymethyl radical, to form the o-hydroxybenzyloxy radical which can lose a hydrogen atom to form o-hydroxybenzaldehyde. The loss of formaldehyde from the $o$-hydroxybenzyloxy radical is not expected to contribute to the formation of phenol on the basis of the rate constant for the $\beta$-scission of benzyloxy radical reported above [14]. Phenol and formaldehyde can be produced from the $\beta$-scission of the $o$ hydroxyphenoxymethyl radical followed by hydrogen abstraction. Mulder has estimated the rate constant for this reaction to be $\log \mathrm{k}\left(\mathrm{s}^{-1}\right)=14-28.4 \mathrm{kcal} \mathrm{mol}^{-1} / 2.303 \mathrm{RT}$ from the ratio of hydroxybenzaldehyde and phenol produced in the pyrolysis of dimethoxybenzene. At $500{ }^{\circ} \mathrm{C}$, the ratio is 3.9:1 [18]. In the FVP of $\mathbf{2}$, the experimentally measured ratio of hydroxybenzaldehyde to phenol is $4.3: 1$, which is in good agreement with Mulder's data. The possibility that phenol arises from the pyrolysis of $o$-hydroxybenzaldehyde was ruled out since $o$-hydroxybenzaldehyde was stable under the reaction conditions. 
reaction may be competitive with the 1,5-hydrogen transfer. Intramolecular hydrogen abstraction from the $\alpha$-carbon forms an intermediate that can cleave to produce styrene and $o$ hydroxyphenoxy radical, which can pick up hydrogen to form catechol. Intramolecular hydrogen abstraction from the $\beta$-carbon produces a radical which can undergo a 1,2-phenyl shift and cleavage to produce $o$-hydroxybenzaldehyde and the benzyl radical. Additional reaction pathways contributing to the formation of catechol are still under investigation.

FVP of 3. The major products from the FVP of 3 are shown below (average mol \% from 3 pyrolyses). The conversion and mass balance for these runs were $9.9 \pm 0.6 \%$ and $99.7 \pm 0.9 \%$, respectively. The second methoxy group accelerates the decomposition of the $\beta-0-4$ linkage (by
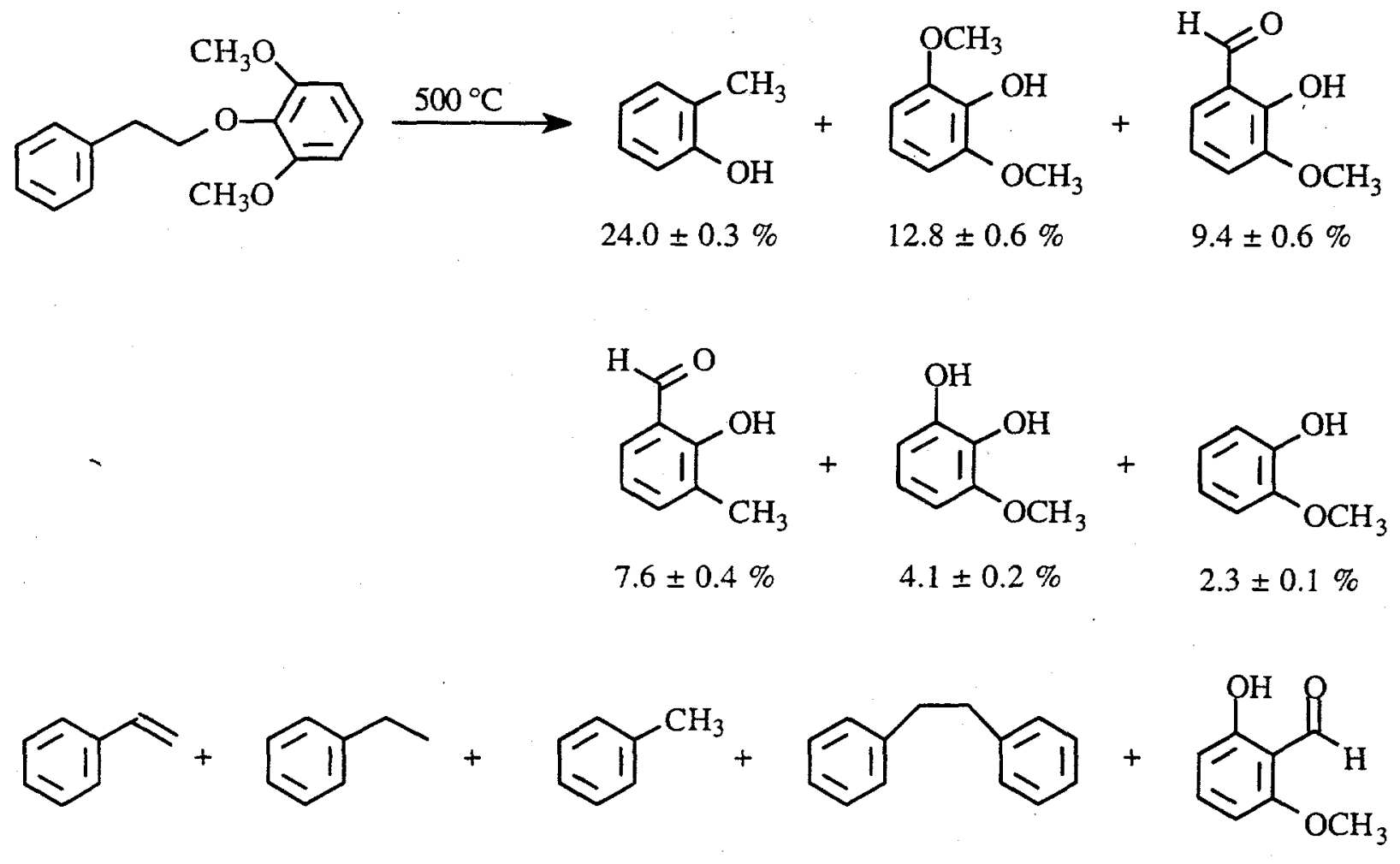

$16.3 \pm 1.3 \% \quad 3.3 \pm 0.1 \% \quad 0.31 \pm 0.02 \% \quad 0.56 \pm 0.01 \% \quad 5.3 \pm 0.2 \%$

a factor of 2.6 compared to 2), but not to the same extent as the first methoxy group. Surprisingly, the major product in the FVP of 3 is $o$-cresol. On the basis of the pyrolysis of 2 , the major product was predicted to be 2-hydroxy-3-methoxybenzaldehyde which was formed in only $9.4 \%$ yield. The reaction pathways of the 2,6-dimethoxyphenoxy radical leading to the formation of $o$-cresol are currently under investigation.

\section{ACKNOWLEDGMENTS}

Research sponsored by the Division of Chemical Sciences, Office of Basic Energy Sciences, U.S. Department of Energy, under contract DE-AC05-96OR22464 with Oak Ridge National Laboratory, managed by Lockheed Martin Energy Research Corp.

\section{REFERENCES}

1. (a) Bridgwater, A. V. (Ed.), Thermochemical Processing of Biomass, Butterworths, London, 1984. (b) Soltes, E. J. and Milne, T. A. (Eds.), Pyrolysis Oils from BiomassProducing, Analyzing, and Upgrading, ACS Symposium Series No 376, American 
Chemical Society, Washington, DC 1988. (c) Goldstein, I. S. (Ed.), Organic Chemical from Biomass, CRC Press, Boca Raton, F1 1981, Chapters 5 and 8.

2. Glasser, W. G.; Sarkanen, S. (Eds.), Lignin Properties and Materials, ACS Symposium Series No. 397, American Chemical Society, Washington, DC, 1989.

3. (a) Elliott, D. C.; Beckman, D.; Bridgwater, A. V.; Diebold, J. P.; Gevert, S. B.; Solantausta, Y. Energy Fuels 1991, 5, 399. (b) Bridgwater, A. V.; Cottam, M-L. Energy Fuels 1992, 6, 113.

4. a) Antal, Jr., M. J. in Boer, K. W. and Duffie, J. A. (Eds.), Advances in Solar Energy, Vol 2, ASES Publication, New Toyk, 1985, p.175 and references therein. (b) Evans, R. J.; Milne, T. A.; Soltys, M. N. J. Anal. Appl. Pyrolysis 1986, 9, 207. (c) van der Hage, E. R. E.; Mulder, M. M.; Boon, J. J. J. Anal. Appl. Pyrolysis 1993, 25, 149.

5. (a) Cooney, M. J.; Britt, P. F.; Buchanan, III, A. C. Prepr. Pap.- Am. Chem. Soc., Div. Fuel Chem. 1997, 42(1), 89. (b) Britt, P. F.; Buchanan, III, A. C.; Malcolm, E. A. J. Org. Chem. 1995, 60, 6523. (c) Britt, P. F.; Buchanan, III, A. C.; Thomas, K. B.; Lee, S.-K. J. Anal. Appl. Pyrolysis 1995, 33, 1.

6. Glasser, W. G.; Glasser, H. R.; Morohoshi, N. Macromolecules 1981, 14, 253. (b) Nimz, H. Angew Chem. Int. Ed. Engl. 1974, 13, 313.

7. (a) Trahanovsky, W. S.; Ong, C. C.; Pataky, J. G.; Weitl, F. L.; Mullen, P. W.; Clardy, J. C.; Hansen, R. S. J. Org. Chem. 1971, 36, 3575. (b) Trahanovsky, W. S.; Ong, C. C.; Lawson, J. A. J. Am. Chem. Soc. 1968, 90, 2839.

8. (a) Brown, R. F. C. Pyrolytic Methods in Organic Chenistry, Academic Press, New York, 1980. (b) Seybold, G. Angew. Chem. Int. Ed. Engl. 1977, 16, 365. (c) Schaden, G. J. Anal. Appl. Pyrolysis 1985, 8, 135. (d) Wiersum, U. E. Rec. Trav. Chim. Pays-Bas 1982, 101, 317 and 365. (e) Hedaya, E. Acc. Chem. Res. 1969, 2, 367. (f) Golden, D. M.; Spokes, G. N.; Benson, S. W. Angew. Chem. Int. Ed. Engl. 1973, 12, 534.

9. In the very low-pressure pyrolysis of diphenyl ether, molecular products (phenol and benzene) were observed by mass spectrometry rather than the radical species. It was proposed that wall associated hydrogen transfer reactions quenched the radical intermediates before arriving at the analyzer. Van Scheppingen, W.; Dorrestijn, E.; Arends, I.; Mulder, P.; Korth, H.-G. J. Phys. Chem.A 1997, 101, 5404.

10. Walker, J. A. ; Tsang, W. J. Phys. Chem. 1990, 94, 3324.

11. Maccoll, A. Chem. Rev. 1969, 69, 33.

12. A $25 \%$ reduction in conversion is predicted for a 1:1 ratio of homolysis to 1,2-elimination. The standard deviations of the $\%$ conversions are $10-20 \%$.

13. Mulcahy, M. F. R.; Tucker, B. G.; Williams, D. J.; Wilmshurst, J. R. Aust. J. Chem. 1967, 20, 1155.

14. Brezinsky, K.; Litzinger, T. A.; Glassman, I. Int. J. Chem. Kinet. 1984, 16, 1053.

15. Suryan, M. M.; Kafafi, S. A.; Stein, S. E. J. Am. Chem. Soc. 1989, 111, 1423.

16. Mallard, W. G; Westly, F.; Herron, J. T.; Hampson, R. F.; Frizzell, D. H. NIST Chemical Kinetics Database: Version 5 National Institute of Standards and Technology, Gathersburg, MD, 1993.

17. a) Martin, G.; Martinez, H.; Ascanio, J. Int. J. Chem. Kinet. 1989, 21, 193. (b) Martin, G.; Martinez, H.; Ascanio, J. Int. J. Chem. Kinet. 1990, 22, 1136.

18. Schráa, G.-J.; Arends, I. W. C. E.; Mulder, P. J. Chem. Soc. Perkin Trans. 2 1994, 189. 
19. The activation energy for the hydrogen abstraction is estimated to be ca. $20 \mathrm{kcal} \mathrm{mol}^{-1}$ based on Arrhenius parameters for hydrogen abstraction reactions in reference $5 \mathrm{~b}$ and $\Delta \mathrm{H}_{\mathrm{rxn}}$ of ca. $9 \mathrm{kcal} \mathrm{mol}^{-1}$. The A-factor for the intramolecular hydrogen abstraction reaction should be larger than that observed in solution (typically $10^{8.5 \pm 0.5} \mathrm{M}^{-1} \mathrm{~s}^{-1}$ ). For example, the A-factor for 1,5-hydrogen shifts in alkyl radicals is $10^{9.2} \mathrm{~s}^{-1}$ (Dobe, S.; Berces, T.; Reti, F.; Marta, F. Int. J. Chem. Kinet. 1987, 19, 895). The A-factor for the intramolecular hydrogen abstraction from 2-methylbenzoyloxy radical to form 2carboxybenzyl radical has been reported to be $10^{10.5} \mathrm{~s}^{-1}$ (Wang, J.; Tsuchiya, M.; Sakuragi, H.; Tokumaru, K. Tetrahedron Lett. 1994, 35, 6321). The cleavage of the methyl group from the methoxyphenoxy radical is estimated to have an activation energy over $40 \mathrm{kcal}$ $\mathrm{mol}^{-1}\left(\Delta \mathrm{H}_{\mathrm{rxn}}=35 \mathrm{kcal} \mathrm{mol}^{-1}\right)$ and the A-factor will be on the order of $10^{14-15} \mathrm{~s}^{-1}$. Using these crude estimates, intramolecular hydrogen abstraction is predicted to be ten-times more favored than cleavage at $500^{\circ} \mathrm{C}$.

20. Viskolcz, B.; Lendvay, G.; Seres, L. J. Phys. Chem. A 1997, 101, 7119. 